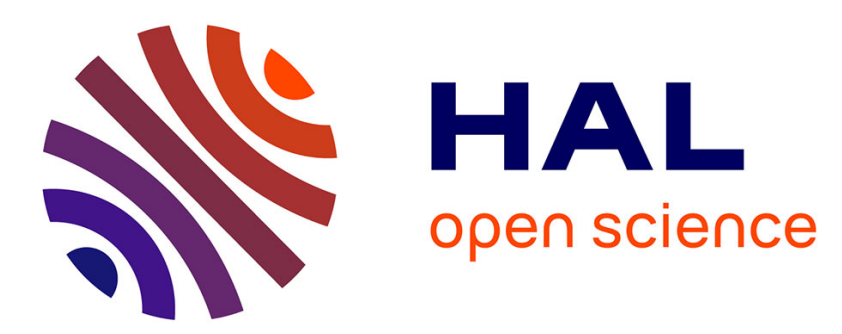

\title{
Multi Layer Modeling of Socio-Technical Production Planning and Control Systems
}

\author{
Adrian E. Specker, Dieter Fischer, Toni Waefler
}

\section{To cite this version:}

Adrian E. Specker, Dieter Fischer, Toni Waefler. Multi Layer Modeling of Socio-Technical Production Planning and Control Systems. IFIP International Conference on Advances in Production Management Systems (APMS), Sep 2014, Ajaccio, France. pp.491-498, 10.1007/978-3-662-44739-0_60 . hal-01388581

\section{HAL Id: hal-01388581 \\ https://inria.hal.science/hal-01388581}

Submitted on 27 Oct 2016

HAL is a multi-disciplinary open access archive for the deposit and dissemination of scientific research documents, whether they are published or not. The documents may come from teaching and research institutions in France or abroad, or from public or private research centers.
L'archive ouverte pluridisciplinaire HAL, est destinée au dépôt et à la diffusion de documents scientifiques de niveau recherche, publiés ou non, émanant des établissements d'enseignement et de recherche français ou étrangers, des laboratoires publics ou privés.

\section{(c)(1)}

Distributed under a Creative Commons Attribution| 4.0 International License 


\title{
Multi Layer Modeling of Socio-Technical Production Planning and Control Systems
}

\author{
Adrian Specker ${ }^{1 *}$, Dieter Fischer ${ }^{1}$, Toni Waefler ${ }^{2}$ \\ ${ }^{1}$ University of Applied Sciences Northwestern Switzerland, School of Engineering \\ Bahnhofstrasse 6, CH-5210 Windisch, Switzerland \\ \{adrian.specker, dieter.fischer\}@fhnw.ch \\ ${ }^{2}$ University of Applied Sciences Northwestern Switzerland, School of Applied \\ Psychology, Riggenbachstrasse 16, CH-4600 Olten, Switzerland \\ toni.waefler@fhnw.ch \\ ${ }^{*}$ Corresponding Author: Prof. Dr. Adrian Specker
}

Keywords: socio-technical systems· modeling· production planning and control· manufacturing

\begin{abstract}
This paper discusses an approach and a proposal of modeling socio-technical production systems. During the analysis and the development of new concepts the need for suitable representation methods emerged. Especially we had to grasp and document varied system aspects and make these aspects understandable for our project team. Surprisingly no standardized, uniform, comprehensive and especially quite complete system modeling standard exists up to the present day. The modeling frame which we developed and which is presented in this paper corresponds first of all to the approach of General System Theory after which complex sociotechnical systems a) can be modeled in a hierarchical structure (called "subsystems") and b) aspect-wise (called "aspect systems"). Within the scope of the project we developed several aspect systems, as for example the formal organization, flow of information, knowledge network and social network.
\end{abstract}

\section{Introduction}

During a project in several manufacturing companies which has been supported by the Swiss Confederation (KTI), the need for suitable representations and a model method emerged in order to support our analysis and conceptual tasks. The project has been about decision support and the optimization of production planning and control tasks and related decisions. During our project work it became (once more) clear, that in an interdisciplinary project regarding production planning and control, unfortunately, one has to develop inevitably "ad hoc" and individually favored representations and modeling technologies. Surprisingly up to the present day no standardized, uniform, comprehensive and "complete" system modeling method exists as an established standard. It is not clear at all with which methods one has to document socio-technical production systems in an integrated way, and how these systems are to be modeled or to be explained. That is, no real methodical certainty exists when a project has to deal with many system aspects. Rather originate within the scope of such projects - in the absence of alternatives and of necessity - more or less new situation-related visualizations. This shows an attempt to do justice to the complexity and

adfa, p. 1, 2011.

(C) Springer-Verlag Berlin Heidelberg 2011 
diversity of the systems to be described. Meanwhile most representation and modeling methods lack an integrating frame, which is why one has to use different and quite separate representations - which lack a clear and recognizable relation between different aspects of the system. The mental integration of different and especially separate representations can therefore not succeed in an optimal way.

Modeling methods, like CIMOSA [1], ARIS [2], SCOR [3], Viable system model VSM [4], UML [5], Value Stream Method - VSM [6] etc. lay their focus mainly on the technical or organizational side. Especially social and cognitive aspect models are not an integrated part of those methods, like e.g. MTO-Analysis [7], Rasmussen [8], Hierarchical Task Model [9], or Knowledge Networks [10].

\section{Problem Statement}

The deficit we face in projects concerning the investigation of "production planning and control systems" depends in fact on our view, to sum it up, that there is no general accepted method to model socio-technical systems which is broad enough to deal with all social, cognitive and technical aspects in an adequate way - or that the methods in use rather negate important social and cognitive aspects. However, the success of projects in such a field depends on the fact, how well the project partners succeed in grasping all those aspects of the production system in order to form a comprehensive conceptual model. Today every successful project like e.g. in construction engineering would be totally inconceivable without high quality, comprehensive construction blueprints.

Models and representations of a socio-technical manufacturing system are not only a topic in the project area. Adequate models would also be valuable for employees who are active in the daily business - as with adequate models they could better understand their enterprise. To eliminate a misunderstanding in advance: Business processes are in many ways mapped or modeled in ERP systems and furthermore there exist quality manuals. However, on the other hand, we found that central factors about the work system are not well documented neither in ERP systems nor in quality manuals (s. below).

\section{Goals and Requirements}

On account of the problem formulation described above and the ascertained deficits, from our point of view the need of a method which documents socio-technical manufacturing systems has arisen. The method should permit therefore in particular taking into account the most different aspects (aspect systems) and integrate them without losing the internal relations to the overall system. The goals are:

- a model of the system hierarchy and its respective levels (system / subsystem)

- an integrated framework for various subsystem and aspect systems

- suitable to model technical and social aspect systems and their interrelations

- expansible to new aspects according to the user's needs

- easy navigation between different aspects and views of the system 


\section{$4 \quad$ Multilayer Modeling Approach}

One purpose of the project consisted in creating an integrating representation meta frame in which different aspect systems at alternatively different system levels can be arranged, without the respective mutual relation gets lost. The system to be visualized must be integrated in a stable frame. As a base of the system representation and in analogy to an architect's plans or construction blueprint a so called "floor plan of the enterprise" served us here. This "floor plan" shows the overall system with his accompanying subsystems. Here, the possibility exists, to illustrate already several layers of the system. In support of the black box representation, known from the system engineering approach quite an easy representation with rectangles was chosen [11].

\subsection{System hierarchy: Systems and Subsystems}

The uppermost representation level shows the overall system, which is called "S(0)". On the level "S(-1)" the system is shown with its subsystems (Fig. 2). In the example (Fig. 1) the system shows an overall system $\mathrm{S}(0)$ of our project partner. Eight departments, like painting, prototypes, logistics, etc., illustrate the according subsystems. With the change of the level $S(0)$ to the level $S(-1)$ the level of detail increases - this step is called "Drill-Down". The requirement of the Drill-Down has been realized in our software tools with the help of hyperlinks as the software tool we used did not support the generation of a hierarchy. In this feature is a major weakness of most graphic tools. Our prototype was provided in Microsoft Visio.
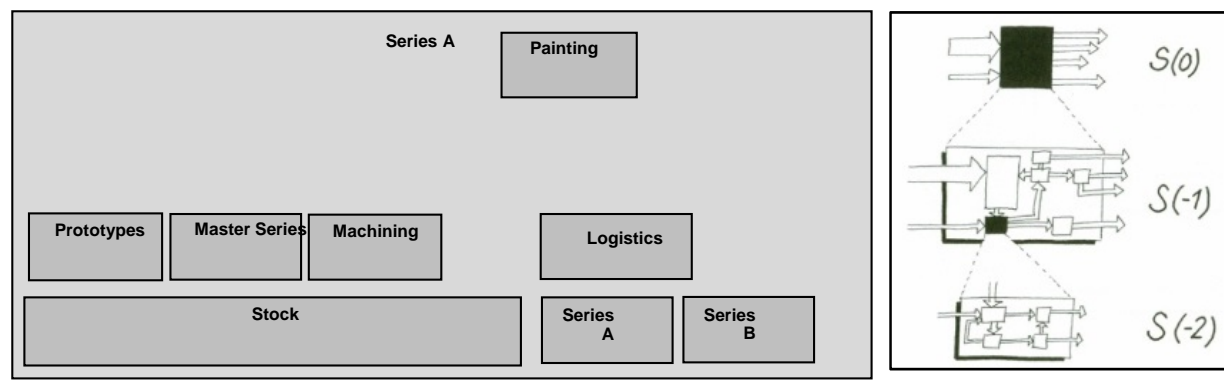

Fig. 2. System levels

Fig. 1. Example of a Level S(-1) system (s. Züst [11])

\subsection{Aspect Systems - Aspect Layers}

The system to be visualized has to be modeled - in order to understand its complexity - with its aspect systems or aspect layers (s. Fig. 3). These aspect layers should be integrated into the pre-existing floor plan as described above. During our project we have been able to derive a first set of these so called aspect layers. They emerged from our different perspectives of the planning and logistics system. There is no sequence in these layers, it is just a set which can vary according to the needs. 


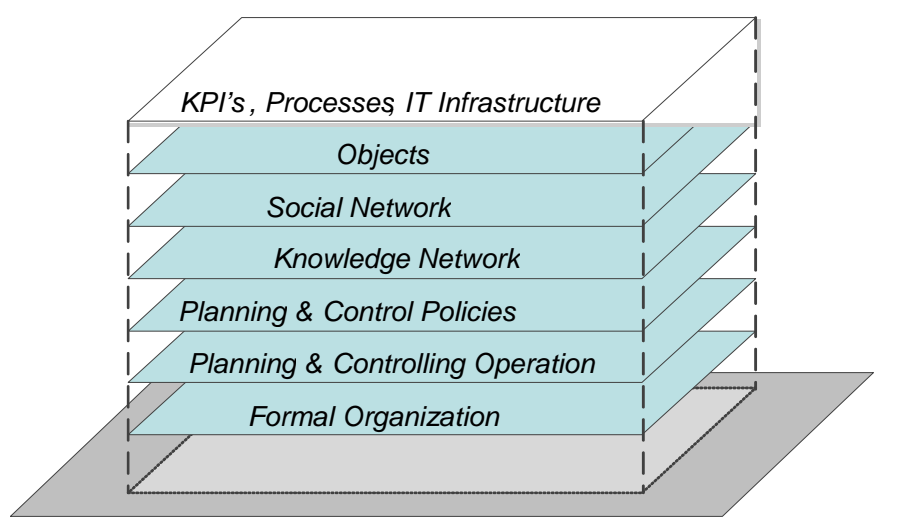

Fig. 3. Aspect Layers of the Socio-Technical System

Table 1. Aspect Layers

\begin{tabular}{|l|l|}
\hline Layer & Description \\
\hline Formal Organization & $\begin{array}{l}\text { The formal organization is a mapping of the hierarchical leading } \\
\text { structures of the company ("floor plan"). }\end{array}$ \\
\hline $\begin{array}{l}\text { Planning and Control } \\
\text { Operations \& Policies }\end{array}$ & $\begin{array}{l}\text { Describes the planning and control system, especially relations } \\
\text { between different elements (push, pull). }\end{array}$ \\
\hline Knowledge Network & $\begin{array}{l}\text { Describes implicit and explicit knowledge elements in relation } \\
\text { with a concrete task or decision. }\end{array}$ \\
\hline Social Network & $\begin{array}{l}\text { Describes the frequency of formal and informal contacts be- } \\
\text { tween different people. The frequency and importance is ana- } \\
\text { lyzed by ratings of the interviewed person. }\end{array}$ \\
\hline Object Layer & $\begin{array}{l}\text { The object layer describes system elements like raw material, } \\
\text { products. }\end{array}$ \\
\hline Process Layer & Describes the relevant business or work processes \\
\hline
\end{tabular}

The number of the aspect layers which can be illustrated is arbitrarily extendable, at least in principle (Tab 1.). Essential is not primary which symbols or which form a single representation uses - here personal preferences may rule. It is much more vital that different aspects in any combination can be faded in and out. This helps the understanding of the system and the successive mental integration of different system aspects and views.

Of course one has to determine well understandable symbols for the representation of these aspect layers. Besides, we tried hard not to invent new symbols or new methods but to use wherever possible already well known symbolic libraries like these from e.g. "Value Stream Modeling" [6]. This simplifies the general intelligibility of the system representation. 


\section{$5 \quad$ Examples of Realized Aspect Layers}

In the following section exemplarily some of the aspect representations realized in the project are described in a more detailed way. An entire documentation of all used representations is not possible, because countless combinations of levels and aspects are possible what leads to a very high number of visualizations of the system [12]. It matters for us to illustrate the basic and fundamental principles of the provided representation method. That is to focus on the internal relation between the different aspect models with the underlying "floor plan".

\subsection{Aspect of Planning and Control}

An essential aspect of the analysis of the production system concerns the analysis of "work order relations" between different shop floors and departments. Work orders can be generated either from of a central planning and control department or as an alternative they can be initialized in a co-operative way (s. Fig. 4). In order to understand the planning and control philosophy one has to analyze the order relations between different systems. In particular we tried also to differentiate so called "push" and "pull" relations. As a "push relation" (straight arrows) we defined in our project relations, where the order-taking department has only a minimal autonomy concerning the timing of the order sequence as a central planning department releases these orders. On the other hand in "pull" relations (circle within the arrow) the order taking place is autonomous. The example below shows the differentiation between several places and departments. According to our notation it becomes evident that some workshops plan with push relations while others maintain only pull relations. We have defined different types of relationships concerning the work orders and have been relating these relations on the preexisting "floor plan". Every line could be augmented by some attributes in order to describe the exact type and purpose. This has been one starting point to document our analysis results. It shows how we have been able to relate our findings into the pre-existing floor plan.

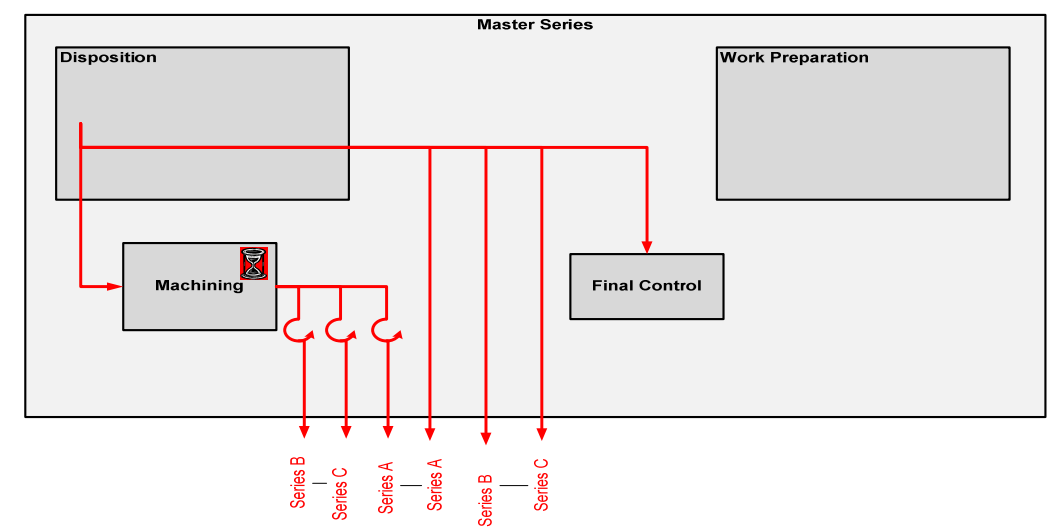

Fig. 4. Relations concerning planning and control - Push- und Pull-relations 


\subsection{Aspect of the Knowledge Network}

As an example of the analysis of a social aspect system, we will illustrate how the so called "knowledge network" [10] could have been integrated into the same "floor plan" as other elements without loosing the representation of the overall system. This analysis concerns the description of existing "knowledge items", that is, which relevant knowledge elements are "instantiated" at the same time for a very specific task. The result is illustrated in Fig. 5. The clouds show "knowledge elements" whereas the lines determine which person uses a certain concept or knowledge element.

In our specific project, the analysis of a "knowledge network" representation has been conducted for several selected specific tasks - in Fig. 5. the task of dealing with a "machine breakdown" is described. This analysis has been carried out by the work psychologists of our group. The results concerning the crucial knowledge and data items could be key to the design of the new ERP-system. This example indicates clearly how one can succeed in inserting a preexisting representation method - the one of the "knowledge network" - into a preexisting "floor plan", without the relation would have gone lost to the overall systems.

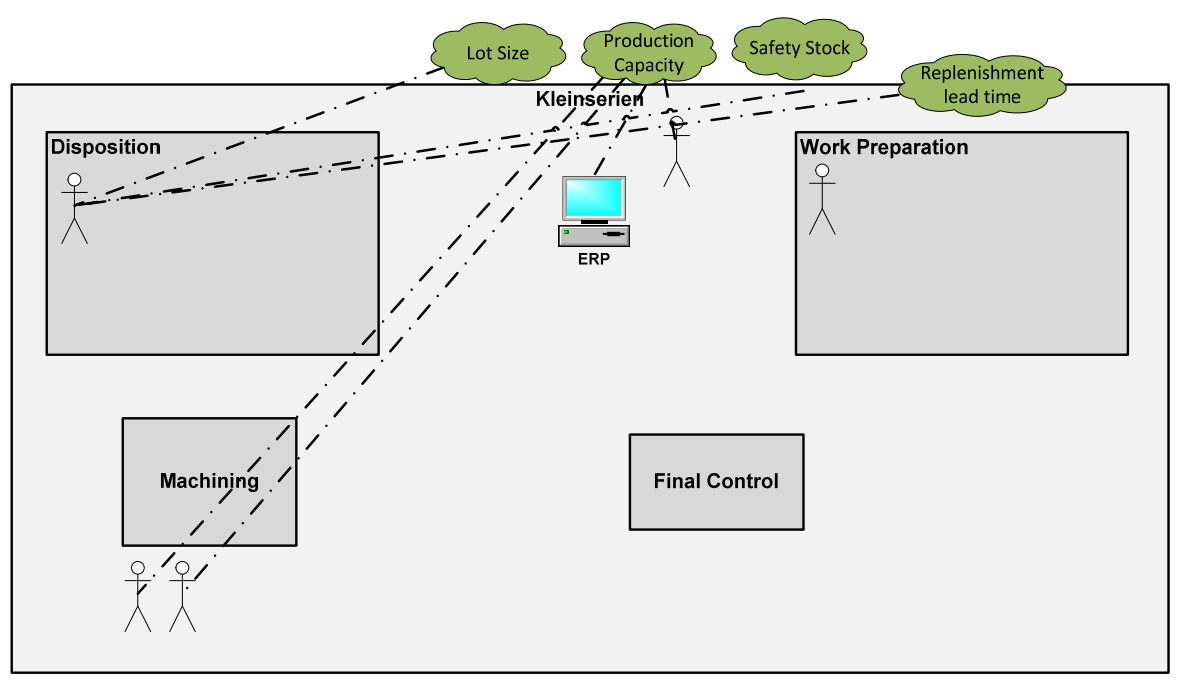

Fig. 5. Knowledge Network in Connection with the Organization and the "Floor Plan"

\subsection{Aspect of the Social Network}

In the area of planning \& control of work orders almost always a so called "secondary network" can be identified [13]. This secondary network is established in order to fulfill the task of coordination of work order as e.g. the optimal timing of work orders. This network maps e.g. the distribution of decision-making competencies or the flow of certain information throughout the company (s. Fig. 6). It can be analyzed by interviews, e.g., by analyzing the frequency and the importance of bilateral relations. 


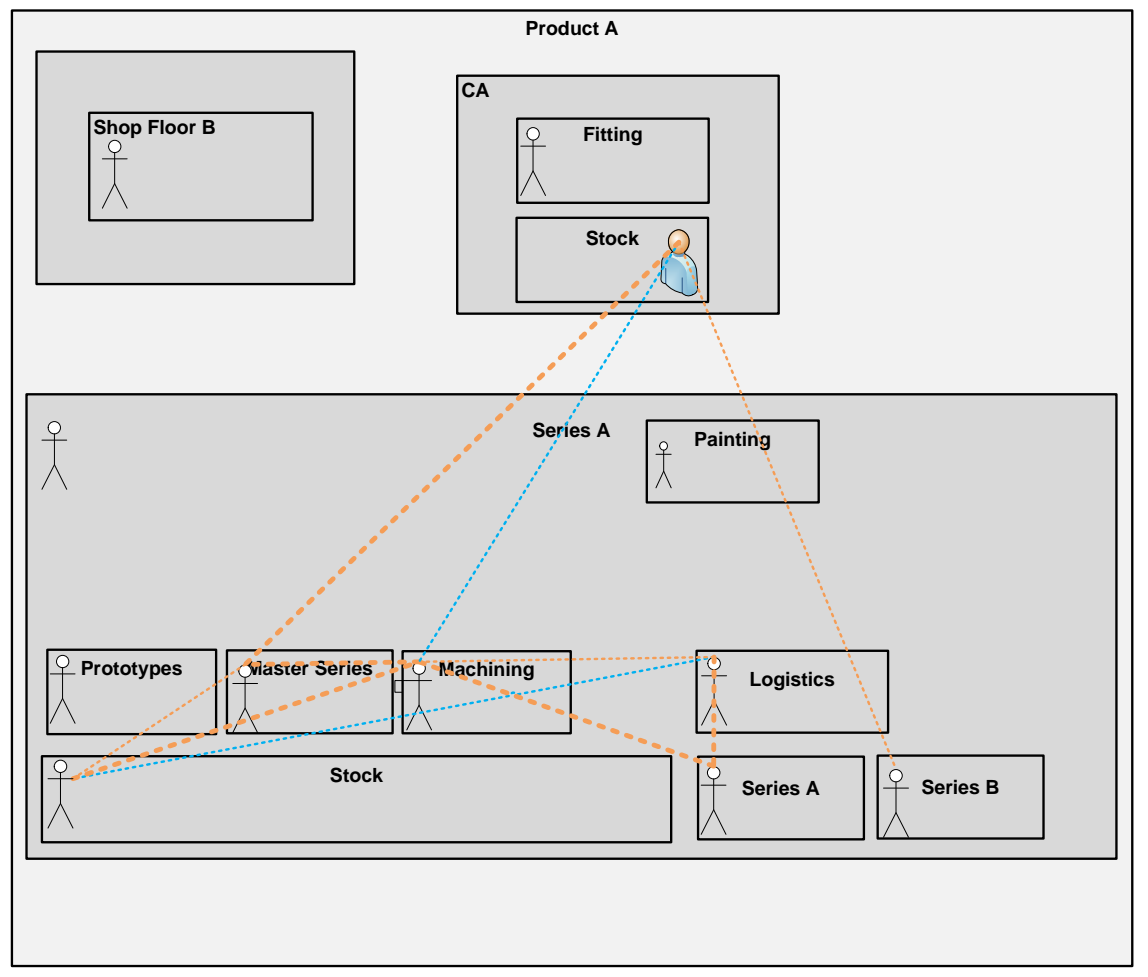

Fig. 6. Social Network

\subsection{Experiences of Practice}

The first experience concerns the software-technical implementation. The second category concerns the aspects of the shown content. The technical category can be characterized by the fact that the chosen software tool used had limited capabilities and supported certain demands only with considerable expenditure - the possibility of a hierarchical and comfortable drill-down was not supported adequately. The chosen software tool (Microsoft Visio) permitted it rather well, to select different aspects layers and to fade them in and out. However, a bigger problem consisted in the fact that new information could be integrated only with quite an effort into the pre-existing "floor plan". The "experience of practice" showed many positive aspects as we have been able to integrate results of work psychologists and industrial engineers.

\section{Conclusion}

The need for an integrated representation method which makes modeling of different aspects of a socio technical system on different layers possible could be fulfilled. It 
could have been shown that many - otherwise rather disjointed representations and models - can be integrated in an overall meta frame. Late changes of the floor plan can cause an effort in order to maintain the picture.

\section{$7 \quad$ References}

1. CIM - Open System Architecture; http://www.cimosa.de

2. Scheer, A.W. (2001): ARIS: Modellierungsmethoden, Metamodelle, Anwendungen. Berlin: Springer.

3. Schnetzler, M, Lemm, R., Bonfils, P., Thees, O. (2009) " Das Supply Chain Operations Reference (SCOR)-Modell zur Beschreibung der Wertschöpfungskette Holz", Allg. Forstu. J.-Ztg, Vol. 180. Nr. 1/2; pp. 1-14.

4. Beer, S. (1962): Kybernetik und Management; Frankfurt am Main: S. Fischer.

5. Burkhard, R. (1997): UML - Unified Modeling Language: Objektorientierte Modellierung für die Praxis. Bonn: Addison Wesley Longman.

6. Hines,P., Rich, N. (1997) "The seven value stream mapping tools", International Journal of Operations \& Production Management, Vol. 17 Iss: 1, pp.46 - 64.

7. Strohm, O., Ulich E. (1997): Ganzheitliche Betriebsanalyse unter Berücksichtigung von Mensch, Technik und Organisation. Vorgehen und Methoden einer Mehr-Ebenen-Analyse (Schriftenreihe Mensch, Technik, Organisation Bd. 10); Zürich: vdf / Stuttgart: Teubner

8. Rasmussen, J. (1986) "Information Processing and Human-Machine Interaction. An Approach to Cognitive Engineering”. New York: North Holland

9. Stammers, R.B., Shepherd, A. (1990): Task Analysis. in: Evaluation of Human Work: A practical Ergonomics Methodology. Wilson, J.R., Corlett, E.N.) London: Taylor \& Francis . pp. $144-168$

10. Stanton, N.A., Stewart, R., Harris, D., Houghton, R.J., Baber, C., McMaster, R., Salmon, P., Hoyle, G., Walker, G., Young, M.S., Linsell, M., Dymott, R. \& Green, D. (2006). Distributed situation awareness in dynamic systems: theoretical development and application of an ergonomics methodology. Ergonomics, 49, 1288-1311

11. Züst, R. (2004). Einstieg ins Systems Engineering, kurz und bündig. Zurich, Verlag orell fuessli; 3. Auflage.

12. Specker, A. (2004) Modellierung von Informationssystemen: Ein methodischer Ansatz zur Projektabwicklung. Zurich, vdf Hochschulverlag, pp. $115 \mathrm{ff}$.

13. Wäfler, T. (2001). Planning and Scheduling in Secondary Work Systems. In: B. MacCarthy \& J. Wilson (Eds.). Human Performance in Planning and Scheduling. London: Taylor \& Francis, pp. 411-447. 